\title{
Etiologia e tratamento das doenças peri-implantares
}

\author{
Etiology and treatment of peri-implant diseases
}

Etiología y tratamiento de enfermedades periimplatorias

Carolina Chaves Gama Aires ${ }^{1 *}$, Jessyca Maria Alencar e Sá2 , Alleson Jamesson da Silva², Amanda Pereira Melo², Demóstenes Alves Diniz², Rennan Antônio Barreto De Abreu², Brenda Rocha Borba de Andrade 2 , Vanessa Lorena do Nascimento', Flávio Murilo Lemos Gondim³, Ricardo José De Holanda Vasconcellos'.

\section{RESUMO}

Objetivo: O propósito do presente estudo foi discutir, através de uma revista da literatura, a etiologia, e os protocolos de tratamento mais indicados para peri-implantite. Revisão bibliográfica: Os implantes osseointegrados vêm sendo cada vez mais utilizados nas reabilitações orais. Apesar da alta taxa de sucesso e longevidade desse tratamento, alguns casos podem ser acometidos por doenças peri-implantares. A periimplantite é uma doença infecciosa bacteriana que afeta tecidos moles e duros em torno do implante, podendo ocasionar a perda da osseointegração. Vários fatores são apontados como causadores da perda óssea periimplantar. Por ser de caráter multifatorial, pode exacerbar a perda de altura óssea, dificultar a cicatrização após cirurgia, e causar a falha do implante. Considerações finais: Os métodos de tratamentos das doenças peri-implantares são os mais diversos possíveis, incluindo modalidades cirúrgicas e não cirúrgicas, além de terapias fotodinâmicas e regenerativas. Por ser uma doença relativamente nova, ainda não há consenso entre os profissionais sobre qual o melhor protocolo de tratamento. Faz-se necessária a realização de novos estudos que possam viabilizar a elaboração de protocolos clínicos para controle e tratamento da periimplantite.

Palavras-chave: Implantes dentários, Peri-implantite, Periodontite, Osseointegração.

\begin{abstract}
Objective: The aim of this study was to discuss, through a literature review, the etiology and the most suitable treatment protocols for peri-implantitis diseases. Literature review: Osseointegrated implants are being increasingly used in oral rehabilitation. Despite the high rate of success and longevity of this treatment, some cases can be affected by peri-implant diseases. Peri-implantitis is a bacterial infection disease that affects soft and hard tissues around the implant, which can cause the loss of osseointegration. Several factors are identified as causing peri-implant bone loss. As it is multifactorial disease, peri-implantitis can exacerbate the loss of bone height, hamper healing after surgery, and cause implant failure. Final considerations: Treatments for peri-implant diseases are diverse as possible, including surgical and non-surgical treatment, photodynamic therapies and regenerative therapies. As it is a relatively new disease, there is still no consensus among professionals on the best treatment protocol. It is necessary conduct researches that can enable the development of clinical protocols for control and treatment of peri-implantitis disease.
\end{abstract}

Keywords: Dental implants, Peri-implantitis, Periodontitis, Osseointegration.

\footnotetext{
${ }^{1}$ Faculdade de Odontologia de Pernambuco - Universidade de Pernambuco (UPE), Recife - PE.

*E-mail: carol20101@gmail.com

2 Universidade Federal de Pernambuco (UFPE), Recife - PE.

${ }^{3}$ Centro Universitário (UNIESP), João Pessoa - PB.
}

SUBMETIDO EM: 6/2020

ACEITO EM: 7/2020

PUBLICADO EM: 11/2020 


\section{RESUMEN}

Objetivo: El propósito del presente estudio fue discutir, mediante una revisión de la literatura, la etiología y los protocolos de tratamiento más adecuados para la periimplantitis. Revisión bibliográfica: los implantes osteointegrados se utilizan cada vez más en la rehabilitación oral. A pesar de la alta tasa de éxito y la longevidad de este tratamiento, algunos casos pueden verse afectados por enfermedades periimplantarias. La periimplantitis es una enfermedad infecciosa bacteriana que afecta los tejidos blandos y duros alrededor del implante, lo que puede promover la pérdida de osteointegración. Se identifican varios factores que causan la pérdida ósea del periimplante, ya que es multifactorial, puede exacerbar la pérdida de la altura del hueso, dificultar la curación después de la cirugía y causar la falla del implante. Consideraciones finales: Los métodos para tratar las enfermedades periimplantarias son lo más diversos posible, incluidas las modalidades quirúrgicas y no quirúrgicas, además de las terapias fotodinámicas y regenerativas. Como es una enfermedad relativamente nueva, no hay consenso entre los profesionales sobre el mejor protocolo de tratamiento. Es necesario realizar nuevos estudios clínicos que permitan el desarrollo de protocolos clínicos para el control y tratamiento de la periimplantitis.

Palabras clave: Implantación dental, Enfermedades periodontales, Periimplantitis, Osteointegración.

\section{INTRODUÇÃO}

A implantodontia é a especialidade odontológica que visa implantar na mandíbula e ou maxila, materiais aloplásticos destinados a suportar próteses unitárias, parciais ou totais, envolvendo um longo tempo de duração do tratamento, custos elevados e a possibilidade de uma série de complicações locais ou sistêmicas durante e após o procedimento, associada a uma alta expectativa do cliente quanto ao resultado (CARDOSO AO, et al., 2010).

Os implantes dentários osseointegrados têm sido bastante utilizados na Odontologia atual com altos índices de sucesso. Desde a introdução dos primeiros implantes, uma série de inovações têm surgido com o objetivo de melhorar os resultados obtidos com esse tratamento reabilitador, sendo a implantodontia considerada um método eficiente de substituição de elementos dentários perdidos (CARDOSO AO, et al., 2010). Além disso, as alterações dos padrões populacionais, com o envelhecimento da população juntamente com os novos parâmetros estéticos aumentam o interesse e aceitação desses procedimentos (FREIRE CNBM, et al., 2017).

Nesse contexto, além da instalação dos implantes, surge a preocupação de mantê-los a longo prazo. 0 acúmulo de placa bacteriana ao redor dos implantes dentários é o fator etiológico mais relacionado com as doenças peri-implantares: as mucosites e peri-implantites. A persistência da inflamação pode resultar na reabsorção óssea em torno do implante, e evoluir com supuração, com presença de bolsas peri-implantares e sangramentos. Fatores como material do implante, comprometimentos sistêmicos e locais do paciente, reação de corpo estranho, habilidade e experiência do profissional são outros dos fatores relacionados a periimplantite (ROSA IMG, 2017).

A peri-implantite é uma infecçao sítio-específica definida como um processo inflamatório que afeta os tecidos ao redor de um implante osseointegrado, resultando em perda do osso de suporte. Esse processo inflamatório, que afeta tecidos duros e moles, é de caráter destrutivo. Clinicamente, pode-se observar a exposição das roscas dos implantes, o que geralmente está associado à destruição óssea ao redor do implante. Os exames de imagem inicialmente podem evidenciar uma lesão em forma de cratera ou taça. Com o avançar da doença, a perda do suporte ósseo torna-se evidente nos exames radiográficos e/ou tomográficos.

O tecido mole que circunda os implantes é denominado mucosa peri-implantar. Apesar das interfaces 'mucosa-implante', bem como a interface 'osso-implante, apresentarem várias características semelhantes àquelas que circundam os elementos dentários, ainda assim, o conjunto apresenta uma composição diferente. Fibras colágenas com orientações e vascularização diferentes e a ausência de ligamento periodontal entre a 
superfície do implante e o tecido ósseo causam uma maior transferência de forças para o osso. Além disso, pode-se observar uma menor irrigação sanguínea quando confrontado com elementos dentários naturais, o que ocasiona um menor aporte de células e nutrientes, que são fatores associados à capacidade de regeneração de tecidos inflamados (SANTOS CA, 2017).

A resposta inflamatória da peri-implantite se divide em duas fases. Inicialmente, ocorre a mucosite periimplantar, uma lesão inflamatória que reside em mucosa. Os seus sinais clínicos são a inflamação e sangramento a sondagem peri-implantar, não ocorrendo perda óssea em torno do implante. Posteriormente, ocorre o estágio da peri-implantite, quadro clínico que engloba a presença de uma lesão inflamatória na mucosa peri-implantar, reabsorção óssea adjacente ao implante e supuração após sondagem. Pode-se constatar também a existência de bolsas peri-implantares com medidas iguais ou superiores a $5 \mathrm{~mm}$ (ROSA IMG, 2017).

Como citado anteriormente, a profundidade de sondagem, sangramento e supuração são os parâmetros clínicos utilizados na detecção destas patologias. Além destes, outros parâmetros como quantidade de mucosa queratinizada e a perda de suporte ósseo visto em radiografias, também podem ser utilizados para avaliar a condição dos tecidos periimplantares (SANTOS OCB e FERRAZ MA, 2017).

A doença periodontal preexistente, deficiência na higiene bucal, tabagismo, a topografia da superfície e o desenho do implante e a qualidade do tecido gengival com o implante são fatores que podem favorecer 0 desenvolvimento da doença peri-implantar (BELLATO A, et al., 2017). Estudos clássicos sugerem que é necessário um mínimo de $2 \mathrm{~mm}$ de mucosa queratinizada ao redor de dentes naturais para a manutenção da saúde dos tecidos gengivais.

A ausência de tecido queratinizado está diretamente relacionada com um maior acúmulo de placa bacteriana. Implantes dentários em regiões com uma faixa estreita de tecido queratinizado, frequentemente exibem um maior acúmulo de biofilme quando comparados a regiões com $2 \mathrm{~mm}$ ou mais de mucosa queratinizada. Um tecido gengival sadio promove uma adaptação íntima do tecido gengival com o implante, acarretando uma mínima reabsorção óssea. Dessa forma, torna-se evidente a importância da saúde gengival para a longevidade dos implantes osseointegrados (TEMMERMAN A, et al., 2018).

Apesar dos implantes dentários demonstrarem resultados favoráveis a longo prazo, os insucessos podem ocorrer. Estudos relatam que 20\% dos pacientes e $10 \%$ dos implantes vão sofrer com essa doença em um período de 5-10 anos após a instalação e após 10 anos, 16\% dos implantes e $26 \%$ dos pacientes (TOLEDO CAO, 2016). Dessa forma, garantir a saúde e estabilidade dos tecidos consiste em um pré-requisito fundamental para prevenir a perda óssea decorrente das doenças peri-implantares. Portanto, o objetivo deste estudo foi discutir a etiologia, e os protocolos de tratamento mais indicados para as doenças peri-implantares, como a peri-implantite, através de uma revisão da literatura baseada em evidências científicas.

\section{REVISÃO BIBLIOGRÁFICA}

\section{Etiologia e fatores de risco}

Os microorganimos presentes em uma mucosa saudável ou infectada em volta de um implante são semelhantes aos que rodeiam um dente hígido ou com doença periodontal. No entanto, a peri-implantite se apresenta de forma mais complexa, sendo uma infecção anaeróbia microbiológica, que pode ser diferenciada da periodontite quando se aborda a composição bacteriana (CARVALHO JP e ROSSI V, 2017).

A microbiologia de um paciente com mucosite peri-implantar é equivalente à gengivite, correlação que não ocorre com a microbiologia da peri-implantite e da periodontite (SANTOS CA, 2019). De uma forma geral, apesar da má higiene oral representar um fator de risco significativo para a doença peri-implantar, ela não representa um risco direto para o desenvolvimento da peri-implantite (CARVALHO JP e ROSSI V, 2017).

Do ponto de vista microbiológico, foram analisadas bactérias colonizadoras na peri-implantite e afirmou que indivíduos portadores dessa patologia são colonizados por patógenos periodontais como Porphyromonas gingivalis, Tannerella forsythia, Fusobacterium nucleatum e Treponema denticola, enquanto sítios peri- 
implantares sadios são colonizados por cocos Gram-positivos (MELO L, et al., 2007). Da mesma forma, Cerbasi KP (2010) listou seis bactérias que seriam responsáveis por essa patologia: Porphyromonas gingivalis, Aggregatibacter actinomycetemcomictans, Prevotella intermedia, Fusobacterium nucleatum, Tanerella forsythia e Campylobacter rectus, e considerou que as mais associadas com a doença periimplantar são Porphyromonas gingivalis, Prevotella intermedia e Aggregartobacter actinomycemcomitans.

Além dos fatores associados a microbiologia que envolve a peri-implantite, diversos elementos possibilitam a perda óssea peri-implantar, dentre eles, a distância entre implantes, doença periodontal, sobrecarga oclusal, espaço na interface pilar/implante, qualidade do tecido mole peri-implantar, relação coroa/implante, localização da junção pilar/implante, características do implante, controle deficiente do biofilme entre outros (DOORNEWAARD R, et al., 2016).

Todos esses fatores devem ser avaliados na tentativa de mensurar o risco de ocorrência de periimplantites. Além desses, fatores relacionados às condições gerais de saúde como: histórico de doença periodontal, tabagismo, diabetes melitus e fatores genéticos (SCHWARZ F, et al., 2018).

Em regiões de mucosa pouco espessa ou pouco queratinizada, uma complicação muito comum é a exposição do 'cover screw' (tampa que recobre a plataforma do implante). Nessas situações, a região periimplantar fica susceptível à infecção bacteriana subclínica, e pode acarretar em dor, abscessos, além de reabsorções ósseas. A presença de próteses traumatizando a região de mucosa também pode facilitar a ocorrência da colonização bacteriana na região peri-implantar (ROMEIRO RL, et al., 2010; MARTINS MM, et al., 2017).

Do ponto de vista biomecânico, achados clínicos e experimentais sustentam a teoria de que forças biomecânicas excessivas podem levar a um alto estresse ou microfraturas na interface osso-implante, o que pode culminar na perda da osseointegração ao redor do implante.

A sobrecarga oclusal pode exercer um papel significante na falha do implante podendo resultar na perda progressiva do osso peri-implantar. Isso fortalece a relevância de se realizar um bom planejamento e consultas de manutenção a fim de garantir a ausência de carga em excesso sobre os implantes.

Apesar da dificuldade de mensurar sobrecarga, acredita-se que este fator torna-se importante em quatro situações clínicas: quando osso que suporta o implante tem pouca qualidade; quando o posicionamento ou a quantidade de implantes não favorece uma distribuição adequada das forças sobre a superfície do implante; quando o paciente tem um padrão de função oclusal sobrecarregada associada a parafunção e ainda quando a estrutura protética não se adapta nos implantes de modo preciso (OLIVEIRA GB, et al., 2013).

O tabagismo e a diabetes melitus frequentemente são associados como fatores de risco para o desenvolvimento de peri-implantite. O consumo do tabaco exerce função importante na patogênese da doença inflamatória, ele também atua na gravidade da doença.

Ao reduzir a vascularização do osso alveolar, interfere na concentração de nutrientes essenciais para o sucesso da osseointegração do implante. Além disso, o tabaco apresenta muitas substâncias tóxicas, tais como nicotina, monóxido de carbono e cianeto de hidrogênio, que podem comprometer a cicatrização óssea após a inserção do implante (CARVALHO JP e ROSSI V, 2017).

A maioria dos estudos apontam o tabagismo e a diabetes como fatores de alto risco para a falha do processo de osseointegração, principalmente quando há história prévia de periodontite. Justamente por serem fatores diretamente relacionados à periodontite, discute-se a real influência destes na patogênese da peri-implantite.

Schwarz F, et al. (2018) concluíram que: enquanto o pobre controle da placa bacteriana e a presença de doença periodontal prévia são fortemente associados com a doença peri-implantar, os estudos que relacionam o tabagismo e a diabetes são inconclusivos. Na tabela 1, encontra-se alguns autores que associaram a perda óssea marginal com a peri-implantite. 
Quadro 1 - Relação entre perda óssea e a peri-implantite.

\begin{tabular}{|c|c|c|c|}
\hline Autores & Ano & Estudo & Achados clínicos \\
\hline Tomas A, et al. & 2016 & $\begin{array}{l}\text { Foi pesquisado entre os anos } \\
2011 \text { - 2015, no Pubmed a } \\
\text { Biblioteca Nacional de Medicina } \\
\text { dos EUA, utilizando como } \\
\text { palavras chaves: Perda óssea, } \\
\text { peri-implantite, e implante } \\
\text { dentário. Foram encontrados } \\
426 \text { trabalhos. Utilizaram } \\
\text { trabalhos que mencionavam a } \\
\text { perda óssea em pacientes com } \\
\text { acompanhamento de pelo } \\
\text { menos } 5 \text { anos. }\end{array}$ & $\begin{array}{l}\text { A perda óssea foi considerada fator } \\
\text { importante relacionado a peri- } \\
\text { implantite. Existe uma média de } 1 \text { a } \\
\text { 3mm de perda óssea nos implantes, } \\
\text { em que a perda acima de } 3 \mathrm{~mm} \text { só } \\
\text { ocorreu em } 5 \% \text { dos casos } \\
\text { estudados com pelo menos } 5 \text { anos } \\
\text { de implantes em função. Alguns } \\
\text { fatores como tabagismo ou doença } \\
\text { periodontal preexistente foram } \\
\text { apontados responsáveis por } \\
\text { aumentarem a risco de perda } \\
\text { óssea. }\end{array}$ \\
\hline Derks J e Tomasi C & 2015 & $\begin{array}{l}\text { Foram selecionados } 277 \text { artigos } \\
\text { sobre peri-implantite, dos quais } \\
\text { foram utilizados } 27 \text {. }\end{array}$ & $\begin{array}{c}\text { Correlacionou a perda óssea com } \\
\text { perda de implantes. Encontrou uma } \\
\text { perda óssea média entre } 0,4 \mathrm{~mm} \text { e } \\
5 \mathrm{~mm} \text {. }\end{array}$ \\
\hline Carvalho JP e Rossi V & 2017 & $\begin{array}{l}\text { Foi realizada uma busca na } \\
\text { base de dados Pubmed, } \\
\text { limitada entre os anos de } 2005 \text { a } \\
\text { 2015. Utilizando como palavra- } \\
\text { chave: peri-implantite. Foram } \\
\text { utilizados ao todo } 21 \text { artigos. }\end{array}$ & $\begin{array}{c}\text { Relataram que a perda óssea } \\
\text { marginal em pacientes fumantes é } \\
\text { duas vezes maior do que nos não } \\
\text { fumantes. }\end{array}$ \\
\hline
\end{tabular}

Fonte: Aires CCG, et al., 2020.

\section{TRATAMENTO}

O tratamento da doença peri-implantar consiste em medidas preventivas e terapêuticas. As medidas preventivas englobam orientação de higiene oral e motivação do paciente, o que não difere das medidas recomendadas para dentes naturais. As medidas terapêuticas são utilizadas quando existe complicações dos tecidos ao redor do implante, com o objetivo de estabelecer um tecido sadio e melhorar o prognóstico dos implantes a longo prazo. Estão incluídos neste grupo, o debridamento mecânico, a descontaminação e condicionamento da superfície do implante, tratamento antimicrobiano, terapia com laser, cirurgia ressectiva, terapias regenerativas e a terapia oclusal (ROMEIRO RL, et al., 2010).

O debridamento mecânico é uma forma de tratamento não cirúrgico realizado sempre que são identificados implantes com alto índice de acúmulo de placa bacteriana, cálculo, tecido peri-implantar inflamado, mas com profundidade de sondagem menor que $3 \mathrm{~mm}$ e sem supuração. Nestes estados os implantes podem ser higienizados mecanicamente utilizando instrumentos manuais ou rotatórios e pasta de polimento.

Os instrumentais utilizados para remover os depósitos de placa bacteriana da superfície dos implantes devem ser macios para não causar danos a superfície dos implantes, como por exemplo, as curetas ou ultrassons com pontas de plástico. Outros métodos citados são a aplicação de ácido cítrico, o jato de bicarbonato (MELO L, et al., 2007; ALCANTARA AAS e ALLEGRINI JS, 2017).

Devido à grande evidência da etiologia bacteriana da peri-implantite, a associação de antissépticos e antibióticos pode ser necessária, pois irá permitir a redução da colonização de bactérias na bolsa periimplantar (CERBARSI KP, 2010; MELO L, et al., 2007). Juntamente com o debridamento mecânico, o uso dos antissépticos, como por exemplo, a aplicação de gel de clorexidina, é indicado em situações que apresentarem acúmulo de biofilme, sangramento a sondagem e quando houver uma profundidade de sondagem entre 4 e 5 mm, havendo ou não supuração (MELO L, et al., 2007; FONTOURA APD, 2015). 
O uso prolongado de antibiótico sistêmico é uma alternativa auxiliar de tratamento quando o uso de antissépticos, associados ou não aos debridamentos mecânicos, não é suficiente para melhora do quadro clínico. Entretanto esta conduta pode resultar em resistência bacteriana (OLIVEIRA GB, et al., 2013; CARVALHO JP e ROSSI V, 2017).

Ao passo que os tratamentos da superfície dos implantes mais modernos possibilitam melhores expectativas na osseointegração, as rugosidades dessas superfícies tornam o processo de descontaminação dos implantes mais difíceis.

Logo, novas formas de descontaminar as superfícies de implantes e tecidos vem sendo utilizada na Odontologia, tais quais o uso de lasers e das radiações ultravioletas (UV). A radiação UV tem um reconhecido papel na diminuição da adesão bacteriana e é amplamente utilizado na medicina como um método de esterilização de superfícies (FLANAGAN D, 2016).

Os lasers podem ser divididos em lasers de alta e baixa potência. Os lasers de alta potência têm a capacidade de coagulação, remoção de tecido e descontaminação, pelo aumento da temperatura (efeito fototérmico). Os lasers de alta intensidade como o $\mathrm{CO}_{2}$, Er:YAG, Nd:YAG e Er,Cr:YSGG, também chamados de cirúrgicos, têm se mostrado muito úteis na remoção do tecido de granulação presentes ao redor de todo o defeito peri-implantar, e por isso tem mostrado resultados promissores no tratamento das peri-implantites (SHIBLI JA, 2014).

Por sua vez, os lasers de baixa potência promovem efeitos fotoquímicos e são empregados para bioestimulação, modulação da inflamação e analgesia, não sendo capazes de remover tecido ou promover a descontaminação, uma vez que não geram aumento da temperatura durante a irradiação. Porém, ao associar o laser de baixa intensidade com um agente fotossensibilizador, criam-se espécies reativas de oxigênio, que em altas concentrações, são tóxicas e promovem a morte de bactérias, fungos e vírus. Esse processo é conhecido como terapia fotodinâmica (PDT).

Os resultados clínicos são bastante satisfatórios, visto que, o laser de baixa potência promove, através da PDT, uma redução bacteriana muito similar ao laser de alta potência, com a vantagem de não promover aumento da temperatura e a um custo mais reduzido (MAROTTI J, et al., 2008). Dessa forma a PDT aparece como uma alternativa em casos onde a descontaminação dos implantes, por meios mais convencionais, se mostra incapaz de eliminar completamente os microrganismos, e possibilitando uma redução bacteriana (SOBREIRA FMSS, et al., 2011).

Nos casos de exposição do "cover-screw", o tratamento mais adequado é a manutenção de uma rigorosa higiene oral e evitar o uso de próteses sobre a região (ROMEIRO RL, et al., 2010). Quando a perda de osso é avançada ou persistente, apesar da realização do tratamento inicial, é necessário debridamento cirúrgico dos tecidos moles peri-implantares juntamente com a descontaminação da superfície do implante. Em casos mais avançados, as aplicações de técnicas de regeneração óssea são necessárias para recuperar o osso perdido (OLIVEIRA GB, et al., 2013).

O tratamento cirúrgico deve ser realizado em regiões onde há perda progressiva de crista óssea ao redor do implante, mas que ainda apresente osso residual para suporte. No ato do procedimento cirúrgico, independente da técnica utilizada, deve ser realizada uma descontaminação da superfície do implante e remoção de todo tecido de granulação (SAWAZAKI JCC, 2011).

Dentre as técnicas de tratamento cirúrgico existem as técnicas ressectiva e regenerativa: a ressectiva pode ser considerada quando o defeito peri-implantar não for apto a receber o tratamento regenerativo. Cirurgia ressectiva é caracterizada pela eliminação da bolsa, através da limpeza em campo aberto, aplainamento dos defeitos ósseos peri-implantares e posicionamento apical do retalho quando necessário.

Todavia, a cirurgia ressectiva o retalho acaba expondo as roscas do implante, e proporcionando um maior acúmulo de placa bacteriana, dificultando a cicatrização e o tratamento da peri-implantite. Nestes casos é realizado a implantoplastia que é a técnica que se realiza o polimento e alisamento das roscas dos implantes. 
A técnica ressectiva promove a redução da profundidade da sondagem e uma anatomia tecidual favorável a higiene, proporcionando tecidos peri-implantares mais saudáveis (MELO L, et al., 2007). A terapia regenerativa tem como objetivo a formação de um osso novo onde há defeito em forma de cratera ao redor dos implantes. Dessa forma, mesmo com uma extensão mais limitada, admite-se que possa ocorrer uma nova osseointegração. Para isso, é necessário um controle da infecção, com redução do edema e ausência de supuração (MELO L, et al., 2007).

A regeneração óssea guiada é utilizada para tratar defeito ósseo circundante ao implante. O seguinte processo envolve a colocação de uma membrana reabsorvível ou não-reabsorvível, associada ou não ao uso de enxertos ósseos, para que ocorra o crescimento de um novo osso, sem que haja a infiltração de tecido mole. Melhores resultados vêm sendo alcançados quando se utiliza material de enxerto ósseo junto com as membranas biológicas (SAWAZAKI JCC, 2011).

As membranas de fibrina ricas em plaquetas e leucócitos (L-PRF) vêm sendo utilizadas como adjuvantes nas técnicas de regeneração óssea guiada. O L-PRF é um coágulo natural otimizado que pode melhorar o processo de cicatrização natural.

Uma matriz de fibrina homogênea e forte rica em plaquetas, leucócitos e células mesenquimais indiferenciadas circulantes, forma um suporte natural complexo, que permite o repovoamento com células do próprio paciente na região do defeito ósseo.

É obtido a partir de uma amostra sanguínea, do próprio paciente, sem adição de nenhum anticoagulante ou ativadores como a heparina, por exemplo, e levado à centrifugação para obter os elementos que podem ser úteis para melhorar a cura e promover a regeneração tecidual (AIRES CCG, 2020).

O L-PRF possui mais de 60 mediadores biológicos, os quais envolvem mecanismos como quimiotaxia, proliferação celular, diferenciação, angiogênese, deposição da matriz intracelular, modulação imune, atividade antimicrobiana e remodelação (SHIBLI, 2014).

Devido a essas características, a membrana de L-PRF é posicionada ao longo da área defeituosa e suturada ao retalho e periósteo subjacente após a exposição e descontaminação da superfície do implante, sendo associada ou não ao preenchimento dos defeitos ósseos com enxertos, e possibilitando a regeneração óssea guiada (SANTOS CA, 2019).

Nas últimas décadas, esforços têm sido feitos na engenharia e medicina regenerativa para produzir métodos seguros e previsíveis nas técnicas regenerativas voltadas para os defeitos alveolares, periodontais ou peri-implantares. Os mediadores biológicos podem ser considerados a geração mais recente e de rápido desenvolvimento de agentes usados na engenharia óssea alveolar.

Amplamente classificados em fatores de crescimento, tais quais fator de crescimento derivado de plaquetas (PDGF), fatores de crescimentos derivados de plaquetas (PDGF), derivados fator de crescimento endotelial vascular (VEGF), fator de crescimento transformador (TGF), da matriz do esmalte (EMD), proteínas morfogenéticas ósseas (BMPs), as células-tronco e os agentes de terapia genética vem sendo reportados na literatura, devido ao seu impacto na regeneração alveolar (LARSSON L, et al., 2016).

Outro ponto importante na medicina regenerativa, é a avaliação sobre o perfil de resposta do hospedeiro em torno de implantes dentários, indicando biomarcadores que fornecem medidas quantificáveis de resposta à terapia peri-implantar. Além disso, um melhor conhecimento do padrão de modulação osteo-imunoinflamatória do hospedeiro na presença de peri-implantite pode beneficiar o diagnóstico precoce da doença ou cooperar com informações prognósticas relacionadas aos defeitos peri-implantares (CÔRREA MG, et al., 2019).

Considerando a ausência de intervenções terapêuticas previsíveis e eficazes para o tratamento da periimplantite, evidências científicas sobre os tipos de tratamento podem ser importantes para fornecer no futuro uma janela preventiva e / ou terapêutica mais ampla para as doenças peri-implantares (CÔRREA MG, et al., 2019). 


\section{CONSIDERAÇÕES FINAIS}

A doença peri-implantar tem um caráter multifatorial e diversas etiologias associadas, o que torna 0 diagnóstico e tratamento desafiadores. A literatura não é padronizada quanto aos parâmetros clínicos para o diagnóstico periodontal/peri-implantar. Diversas metodologias são empregadas e pode-se notar uma divergência nas mesmas, tornando difícil a uniformização dos protocolos, e, portanto, dos resultados. Ainda não existe um consenso sobre qual o melhor protocolo de tratamento e qual o momento ideal da intervenção cirúrgica, como também em relação ao uso ou não de técnicas regenerativas. É de fundamental importância o conhecimento das variadas alternativas terapêuticas utilizadas no cenário atual e suas respectivas aplicações. Como ainda não se sabe qual o melhor tipo de tratamento das doenças peri-implantares, novos estudos tem uma relevância significativa. Portanto, faz-se necessária a realização de ensaios clínicos e estudos de coorte, que possam viabilizar a elaboração de protocolos clínicos para prevenção, controle e tratamento da peri-implantite.

\section{REFERÊNCIAS}

1. AIRES CCG, et al. Terapias regenerativas em implantodontia: avanços no uso da Fibrina rica em plaquetas (PRF). Revista eletrônica acervo saúde, 2020. 39; e2393.

2. ALCÃNTARA AAS, ALLEGRINI JS. Periimplantite terapia fotodinâmica. Revista Ibirapuera, 2017; 13: 17-23.

3. CARDOSO AO, et al. Etiologia e tratamento das doenças periimplantares. Odonto 2010;18(36):59-66.

4. CARVALHO JP, ROSSI V. Influência do tabagismo em doenças Peri-implantares. Stomatos, $2017 ; 23(44): 41-47$.

5. CERBASI KP. Etiologia bacteriana e tratamento da peri-implantite. Innov Implant J, 2010; 5(1): 50-55.

6. CÔRREA MG, et al. Host response and peri-implantitis. Braz Oral Res, 2019. 30; 33(1): e066.

7. DERKS J, TOMASI C. Peri-implant health and disease. A systematic review of current epidemiology. J Clin Periodontol, 2015; 42(16): 158-171.

8. DOORNEWAARD R, et al. Long-Term Effect of Surface Roughness and Patients' Factors on Crestal Bone Loss at Dental Implants. A Systematic Review and Meta-Analysis. Clinical Implant Dentistry and Related Research, 2016; 19(2): 372-399.

9. FLANAGAN D. Photofunctionalization of dental implants. J Oral Implantol. 2016 Oct;42(5):445-450.

10. FONTOURA APD. Tratamento para Peri-implantite: uma revisão de literatura. Dissertação (Especialização em Periodontia) - Instituto de Periodontia. Escola Bahiana de Medicina e Saúde Pública, Salvador, 2015.

11. FREIRE CNBM, et al. Complicações decorrentes da reabilitação com implantes dentários. Revista UNINGÁ, 2017; 51(3): 63-68.

12. LARSSON L, et al. Regenerative Medicine for Periodontal and Peri-implant Diseases. J Dent Res, 2016; 95(3): 25566.

13. MAROTTI J, et al. Terapia fotodinâmica no tratamento da periimplantite. Revista implantnews, 2008; 5(4):401-5.

14. MARTINS MM, et al. inter-relação das plataformas dos implantes dentários com a doença peri-implantar. Revista de divulgação da ULBRA Torres, 2017; 1678-1740.

15. MELO L, et al. Microbiologia das doenças periimplantares: revisão de literatura. Revista de Odontologia da UNESP, 2007; 36(1): 61-9.

16. OLIVEIRA GB, et al. Peri-implantite: considerações sobre etiologia e tratamento. Arq. Ciênc. Saúde UNIPAR, 2013; 17(1): 55-59.

17. ROMEIRO RL, et al. Etiologia e tratamento das doenças periimplantares. Odonto, 2010; 18(36): 59-66.

18. ROSA IMG. Etiologia da peri implantite. Dissertação (Mestrado em medicina dentária) - Faculdade de ciências da saúde, Porto, 2017.

19. SANTOS CA. Novas abordagens no tratamento da periimplantite. Dissertação (Mestrado em Medicina Dentária) Faculdade de Medicina Dentária. Universidade do Porto, Portugal, 2019.

20. SANTOS OCB, FERRAZ MA. Correlações entre parâmetros clínicos e doenças periimplantares: revisão de literatura. BBO-Dentistry,2017; 27(3): 37-43.

21. SAWAZAKI JCC. Periimplantite: diagnóstico e tratamento. Dissertação - Faculdade de Odontologia de Piracicaba. Universidade Estadual de Campinas, São Paulo, 2011.

22. SCHWARZ F, et al. Peri-implantites. J Clin Periodontol, 2018; 45 (20): 246-266.

23. SHIBLI JA. Tratamento de peri-implantite utilizando fibrina rica em plaquetas e leocócitos (L-PRF), e laser de ER, CR: YSGG. Perionews, 2014; 8(4):391-395.

24. SOBREIRA FMSS, et al. Periimplantite: Base científica para diagnóstico e tratamento. International Journal of Dentisty, 2011; 10(3): 180-185.

25. TEMMERMAN A, et al. L-PRF for increasing the width of keratinized mucosa around implants: A split-mouth, randomized, controlled pilot clinical trial. J Periodontal Res. 2018 Oct;53(5):793-800.

26. TOLEDO CAO. Periimplantite: epidemiologia, etiologia e tratamento: uma revisão narrativa. Dissertação (Graduação) - Faculdade de ciências da saúde. Universidade de Brasília, 2016.

27. TOMAS A, et al. "Peri-implantitis": A complication of a foreign body or a man-made "disease". Facts and fiction. Clin Implant Dent Relat Res, 2016; 18(4) 840-9. 